\title{
La poesía en "La Gitanilla": ¿Es Preciosa "Algo DESENVUELTA, PERO NO DE MODO QUE DESCUBRIESE ALGÚN GÉNERO DE DESHONESTIDAD"?
}

\author{
BÉNÉDICTE TORRES \\ Université de Lille
}

Title: Poetry in La gitanilla : "Is Preciosa's confidence undermined by her revealing of some form of dishonesty?"

Abstract: This essay, which follows an article written by Monique Joly and Francisco Márquez Villanueva, underlines the way Cervantes used poetry to free the speech of a female character: a little gipsy girl whose noble origins are revealed at the end of this exemplary novel. The recurring praise of Preciosa's honesty is opposed to several dissonances through metaphorical and ambiguous expressions serving as a tool of protest against a hierarchical, unfair and hypocritical society. This protest finds its highest form in the verses devoted to fortune-telling. Preciosa, identified as poetry, embodies a freedom much cherished by Cervantes, a means to create and re-create by playing with the literary codes of the time. The end of this analysis brings up a comparison between the voices of Preciosa and Altisidora, who in I6Is Quixote reveals herself as an expert in the art of verbal deceit, as in the verses from chapters 44 and 57 .

Key words: Poetry. Dissonance. Freedom. Protest

El artículo de Monique Joly titulado "En torno a las antologías poéticas de La gitanilla y La ilustre fregona" ha sido punto de partida y fuente de inspiración de esta reflexión como un homenaje más a quien fue mi profesora, mi primera directora de tesis y también mi colega en la universidad de Lille. Como indica el título de mi trabajo, me centraré exclusivamente en los poemas dichos, leídos y cantados en la primera novela ejemplar.

Después de presentar el corpus poético que destaca por su abundancia y su diversidad, contemplaré cómo se inserta en la prosa y a quién se atribuye la autoría de cada poema. Luego intentaré mostrar cómo los versos se convierten en un espacio privilegiado donde se manifiesta tanto la gitanilla, quizás más desenvuelta de lo que se suele afirmar, como la noble Costanza. Terminaré por unas reflexiones sobre el papel concedido por Cervantes a la poesía en el retrato de figuras femeninas como Preciosa y Altisidora, supuestamente enamorada de don Quijote durante su estancia en el palacio ducal. 
En su artículo ya citado y publicado en i993, Monique Joly desea ofrecer una reconsideración de conjunto y una confrontación de las poesías presentes en La gitanilla y La ilustre fregona cuya abundancia le parece un rasgo específico de esas dos novelas frente a las demás novelas ejemplares. Adopta una perspectiva diferente de la de otros críticos: Alban Forcione que relaciona las poesías de La gitanilla con las del Persiles, ${ }^{1}$ Joaquín Casalduero para quien Preciosa es símbolo de la honestidad y encarnación del ideal moral de lo femenino en la Contrarreforma ${ }^{2}$ y Marcel Bataillon en lo que se refiere a las mozas de mesón en La ilustre fregona.

Apoyándose en la lectura que hace Francisco Márquez Villanueva de la buenaventura de Preciosa, Monique Joly se interroga sobre la introducción de "un contrapunto deliberadamente disonante y procaz" en los poemas de ambas novelas. Seguiré humildemente sus pasos, fijándome, como he dicho anteriormente, en los versos de La gitanilla.

En esta novela ejemplar aparecen nueve intercalaciones poéticas presentadas así por Joly: el romance de Preciosa a Santa Ana (cantado y bailado), el intercambio de réplicas en el que se cita el cantarcillo tradicional Pisaré yo el polvico..., el romance de Preciosa a la reina Margarita (cantado y bailado), el romance a Preciosa (primer poema del paje, leído), la buenaventura de Preciosa, el soneto a Preciosa (segundo poema del paje, leído), el ensalmo, el canto amebeo de Andrés y Clemente y la respuesta de Preciosa (cantada). Esta lista da cuenta de la diversidad tanto de los temas tratados (religiosos, regios y amorosos) como del origen popular o culto de los versos. La buenaventura se relaciona con la condición gitana de la protagonista así como el ensalmo. Es de notar una evolución a lo largo de la novela entre los primeros poemas dedicados a figuras ajenas a la diégesis (Santa Ana, la reina Margarita) y los siguientes que atañen a los protagonistas. Paralela-

${ }^{\mathrm{I}}$ Forcione (1982, 193-222).

${ }^{2}$ Casalduero (I 969:56-77). 
mente, los primeros se cantan ante un auditorio numeroso congregado en lugares públicos mientras que los otros en casas particulares, con excepción del canto amebeo y de la respuesta de Preciosa que se cantan de noche y en la soledad de un bosque.

Podemos observar la alternancia entre las tres poesías de tono amoroso dedicadas a Preciosa leídas o cantadas y los poemas dichos o cantados por ella. Llama la atención también el lugar central ocupado por la buenaventura que ha dado lugar a distintas interpretaciones sobre las que volveremos más adelante.

Si la autoría de los poemas en honor de la gitanilla es clara (el pajepoeta, llamado después Clemente y Andrés), cabe preguntarse si ésta es intérprete o improvisadora. La buenaventura y el ensalmo parecen ser improvisaciones suyas mientras que el romance a la reina Margarita se atribuye a "un poeta de los del número, como capitán del batallón”. Nada se dice sobre el autor del romance a Santa Ana y la respuesta al canto amebeo viene precedida por estas advertencias del narrador:

Ella (o no sé si de improviso, o si en algún tiempo los versos que cantaba le compusieron) con estremada gracia, como si para responderles fueran hechos, cantó los siguientes... ${ }^{3}$

Pero lo que diferencia los dos primeros romances a Santa Ana y a la reina Margarita de los demás poemas es que no solo se cantan sino que se bailan. Si el narrador en las primeras líneas de la novela presenta a Preciosa como "la más única bailadora que se hallaba en todo el gitanismo", antes del romance a Santa Ana, indica que su pericia le vale "el premio y joya de la mejor danza” (P.3 I) y después afirma:

Acabáronse las vísperas y la fiesta de Santa Ana, y quedó Preciosa cansada, pero tan celebrada de hermosa, de aguda y de discreta, y de bailadora, que a corrillos se hablaba della en toda la corte" (P. 33).

${ }^{3}$ Las referencias corresponden a Cervantes (2001:93). 
El polisíndeton pone de realce las cualidades de la gitanilla y, en particular, su talento coreográfico que sobresale al final de la enumeración. En el poema del paje se hace hincapié también en éste:

[...] pues bailando nos admiras,

y nos matas, si nos miras.

Nadie lee estos elogios sin tener presente la connotación erótica que el baile tenía en aquella época en que se diferenciaba de la danza más acompasada, honesta y señoril. De manera paradójica, el baile acompaña las dos poesías más serias de toda la novela, dedicadas a una santa y a una reina.

Al final del romance a Santa Ana, la ligereza de Preciosa al bailar podría interpretarse en clave erótica si se recuerda la acepción de polvo (coito, fornicio) quizás oculta detrás de la alusión al popular baile del polvico o polvillo como lo sugiere Francisco Márquez Villanueva. ${ }^{4}$

He aquí las réplicas a las que me refiero:

Otro más humano, más basto y más modorro, viéndola andar tan ligera en el baile, le dijo: "¡A ello, hija, a ello! ¡Andad, amores, y pisad el polvillo atán menudito!" Y ella respondió, sin dejar el baile: “iY pisárelo yo atán menudó !" (P. 33).

En el entremés de La elección de los alcaldes de Daganzo, Cervantes recoge la letra de dicho baile:

Pisaré yo el polvico

atán menudico;

pisaré yo el polvo

atán menudó.

Pisaré yo la tierra, por más que esté dura, puesto que me abra en ella amor sepultura,

4Márquez Villanueva (i 985 / I 986 :74I-768 y 755). La palabra “polvo” no aparece documentada en Alzieu, Lissorgues y Jammes (1975). 
pues ya mi buena ventura

amor la pisó.

Atán menudó.

Pisaré yo lozana

el más duro suelo, si en él acaso pisas

el mal que recelo.

Mi bien se ha pasado en vuelo,

y el polvo dejó.

Atán menudó. ${ }^{5}$

Y es uno de los bailes que critica Pedro Sánchez en su obra Historia moral y philosóphica publicada en I 589:

Y ¿qué cordura puede haber en la mujer que en estos diabólicos ejercicios sale de la composición y mesura que debe a su honestidad, descubriendo con saltos los pechos y los pies, y aquellas cosas que la naturaleza o el arte ordenó que anduviesen cubiertas? ¿Qué diré del halconear con los ojos, del revolver las cervices y andar coleando los cabellos, ya dar vueltas a la redonda, ya hacer visajes, como acaece en la zarabanda, polvillo, chacona y otras danzas? ${ }^{6}$

No dejan de sorprender además las frases que introducen el romance a la reina Margarita, esposa de Felipe III, con motivo de su salida a misa de parida:

Hecho, pues, su agosto y su vendimia, repicó Preciosa sus sonajas, y al tono correntío y loquesco cantó el siguiente romance (P. 34).

Según Jorge García López, “correntío” se relacionaría con los “corridos”, nombre que se da a los romances monorrimos en Andalucía y América. El empleo del adjetivo "loquesco" para calificar el tono de ejecución contrasta con el tema del romance que parece ser una alabanza de la familia real. Quizás vaya sembrando el narrador unos indicios de ambigüedad detrás de la gravedad aparente:

${ }^{5}$ Cervantes (I 999: I I 35).

${ }^{6}$ Esta denuncia de Pedro Sánchez viene citada en Deleito y Piñuela (1 966:77). 


\section{Preciosa baila a petición del teniente después de la buenaventura:}

[... él las hizo bailar un poco y confirmó por verdaderas y bien dadas las alabanzas que a Preciosa habían dado [...] (P. 5o).

Y también a petición del padre de Andrés:

No os enojéis, Preciosa - dijo el padre- que, a lo menos de vos, imagino que no se puede presumir cosa mala, que vuestro buen rostro acredita y sale fiador de vuestras buenas obras. Por vida de Preciosita, que bailéis un poco con vuestras compañeras... (P. 65).

Es de notar que son hombres los que le invitan a bailar, como si disfrutaran particularmente del espectáculo. Las palabras del padre de Andrés reflejan, a mi parecer, de modo significativo, ese juego de luces que atenúa, aunque no dejando de sugerirlas, las connotaciones eróticas del baile que parece ser una actividad en la que la gitanilla sobresale. La insistencia en los pies de Preciosa confirma la erotización del elogio siguiente:

Tomó las sonajas Preciosa, y dieron sus vueltas, hicieron y deshicieron todos sus lazos, con tanto donaire y desenvoltura, que tras los pies se llevaban los ojos de cuantos la miraban, especialmente los de Andrés, que así se iban entre los pies de Preciosa como si allí tuvieran el centro de su gloria. (P. 65).

Cabe destacar que la palabra "desenvoltura", asociada aquí al donaire, se relaciona con la honestidad en momentos claves del texto. El retrato inicial de Preciosa concluye, en efecto, así:

$\mathrm{Y}$ con todo esto, era algo desenvuelta, pero no de modo que descubriese algún género de deshonestidad; antes, con ser aguda, era tan honesta que en su presencia no osaba alguna gitana, vieja ni moza, cantar cantares lascivos ni decir palabras no buenas. (P. 29).

Me refiero también a la conversación con Andrés que está dispuesto a ser gitano por amor: 
Sepa que conmigo ha de andar siempre la libertad desenfadada, sin que la ahogue ni turbe la pesadumbre de los celos; y entienda que no la tomaré tan demasiada que no se eche de ver bien lejos que llega mi honestidad a mi desenvoltura. (P. 56).

La equiparación entre honestidad y desenvoltura lleva a cuestionar los límites de cada una y abre un espacio de posibilidades con el que juega el narrador al insistir a menudo en la honestidad de Preciosa y al calificar a Juana Carducha que encarna la deshonestidad de "algo más desenvuelta que hermosa" (P. 94).

Las frecuentes ocurrencias de "honestidad" (seis en total, pp. 56, 79, 91, 93, 94, IO2) y del adjetivo "honesto" (empleado ocho veces para calificar a Preciosa, pp. 29, 33, 40, 66, 79, 82, 93, 98) han contribuido sin duda a la visión idealizada de la protagonista y han hecho pasar por alto la filiación diabólica de las gitanas. La misma Preciosa declara en efecto:

No hay muchacha de doce que no sepa lo que de veinte y cinco, porque tienen por maestros y preceptores al diablo y al uso, que les enseña en una hora lo que habían de aprender en un año. (P. 44).

y el teniente antes de que las gitanas se despidan de su familia, exclama: “ $\mathrm{El}$ diablo tienen estas gitanas en el cuerpo!” (P. 5 I ). Pero las palabras de la gitana vieja a propósito de Preciosa, que acaba de afirmar que llega su honestidad a su desenvoltura, cobran un relieve particular:

¡Satanás tienes en tu pecho, muchacha! -dijo a esta sazón la gitana viejaMira que dices cosas que no las diría un colegial de Salamanca! Tú sabes de amor, tú sabes de celos, tú de confianzas; ¿Cómo es esto, que me tienes loca, y te estoy escuchando como a una persona espiritada que habla latín sin saberlo? (P. 56).

Covarrubias en su diccionario precisa que "espiritado" equivale a endemoniado. No puede ser gratuita ni fortuita la referencia a Lucifer en las páginas que preceden o siguen la buenaventura donde no falta osadía ni irreverencia. Esta caracterización de Preciosa ofrecida tanto por un payo como 
por una misma gitana parece ser un eco de la visión que la sociedad española contemporánea tenía de la gitanería y es como una advertencia al lector que no es tan perfecto el retrato de la protagonista como parece ser de buenas a primeras. Las numerosas afirmaciones de la honestidad de Preciosa a lo largo de la novela se pondrían en tela de juicio en el espacio poético caracterizado por una mayor libertad de expresión como lo subrayó Agustín González de Amezúa y Mayo al referirse a "la inclusión de ciertos pasajes maliciosos, picantes y equívocos” en La gitanilla:

Todos ellos contiénense en la buenaventura que Preciosa lee en la mano de la mujer del Teniente de la Villa, aunque les sirva de excusa el ser imitación del estilo libre y desenvuelto que las gitanas empleaban en las suyas. Verdad es también que en aquellos tiempos tolerábanse más estas licencias en el verso que en la prosa. ${ }^{7}$

En un artículo dedicado a "la buenaventura de Preciosa", Francisco Márquez Villanueva considera estos versos como "l'enfant terrible" de los poemas cervantinos e indica como precedente el de Eufemia ( I 567) de Lope de Rueda. Las predicciones de rigor aluden a las herencias, a unas relaciones matrimoniales poco sinceras por ser "juguetón” el teniente que "quiere arrimar la vara”, expresión de clara connotación erótica. Se confirma así la afirmación anterior de Preciosa:

[... más te quiere tu marido que el rey de las Alpujarras.

Si se opta por ver en este rey un "mero signo de personaje fabuloso", es decir, en realidad un rey inexistente. Por fin, la buenaventura hace referencia a los hijos: un hijo canónigo pero no en Toledo, según se precisa, por impedirlo probablemente el origen converso de doña Clara, y una hija 'perlada", es decir prelada que en el lenguaje germanesco significa prostituta. Pero en estos versos destaca una etopeya y hasta cierto punto una

\footnotetext{
${ }^{7}$ González de Amezúa y Mayo (1948, 2:3 I).
} 
prosopografía de doña Clara, inestable, caprichosa, celosa, asimilada tanto a una paloma como a una leona y a un tigre, lo que contribuye a su deshumanización. Las referencias corporales a sus manos de plata al principio de la buenaventura y al lunar al final son de cariz erótico.

Con la alusión a este, Cervantes juega irónicamente con ciertas tradiciones genealógicas y heroicas de signo regio, con el motivo del naevus luminoso presente en unas novelas de caballerías españolas: ${ }^{8}$

Un lunar tienes, ¡qué lindo!

¡Ay, Jesús, qué luna clara!

¡Qué sol, que allá en los antípodas

Escuros valles aclara!

Más de dos ciegos por verle

Dieran más de cuatro blancas. (P. 49).

El juego entre lunar y luna, entre luna y sol (cunnus), la alusión a los oscuros valles que delinean una geografía corporal sobreentienden la unión de lo masculino y femenino y por lo tanto maliciosamente sugieren la vida galante de doña Clara con unos hombres ciegos de amor. Lo mismo podemos decir de la advertencia contra las caídas de espaldas. Preciosa domina tanto el arte de las bernardinas ${ }^{9}$ como el de la pulla que Monique Joly estudió detenidamente en su libro La bourle et son interprétation. Recherches sur le passage de la facétie au roman. ${ }^{\text {Io }}$

La pulla tiene una intención punzante, burlescamente ofensiva destinada a humillar y avergonzar. La pareja del teniente sale, pues, muy malparada de esta denuncia corrosiva que juega con la polisemia, lo pleno y lo vacío, como vimos con la alusión al rey de las Alpujarras. La libertad expresiva de

8Delpech (1990).

${ }^{9}$ Sobejano (1966).

Io Véase Joly (I 982:I38-142) para las bernardinas que Sebastián de Covarrubias (I6 I I) define así: "unas razones que ni atan ni desatan, y no significando nada, pretende el que las dice, con su disimulación engañar a los que están oyendo“. La pulla es objeto de reflexiones en Joly (1982: 247 y 267. 
Preciosa es una respuesta en realidad muy agresiva a la burla y al desdén de la que es víctima por parte de quien representa un poder destructor y absoluto. A través de ella, Cervantes, por una parte, condenaría la hipocresía de las relaciones entre el teniente y su pareja, la venalidad del ministro de la justicia y, por otra parte, defendería la dignidad de los marginados. ${ }^{\text {II }}$

El matrimonio pervertido de doña Clara se opone totalmente a las aspiraciones de amor puro expresadas por Preciosa ya desde las poesías iniciales. El retrato feroz del teniente y de su esposa revela una osadía e irreverencia que es un contrapunto a la honestidad tantas veces ponderada de la protagonista. La desenvoltura parece exceder el recato en esos versos de la buenaventura, los únicos tan disonantes en el ambiente idealizado de la novela. Esta libertad sería posible por ser la voz de la gitana y no la de la noble Costanza.

El ensalmo que pronuncia Preciosa cuando Andrés está a punto de desmayarse al oír el soneto del paje-poeta puede ser otra expresión de las prácticas supersticiosas atribuidas a las gitanas pero su tonalidad dista de la de la buenaventura:

Cabecita, cabecita, tente en ti, no te resbales, y apareja dos puntales de la paciencia bendita.

Solicita

la bonita confiancita; no te inclines a pensamientos ruines;

verás cosas que toquen en milagrosas, Dios delante Y San Cristóbal gigante. (P. 67).

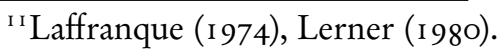


"Es de notar que no son estas las palabras que Preciosa” dice al oído de Andrés sino las siguientes pronunciadas “casi sin mover los labios”:

- “ ¡Gentil ánimo para gitano ! ¿Cómo podréis, Andrés, sufrir el tormento de toca, pues no podéis llevar el de un papel ? Y haciéndole media docena de cruces sobre el corazón, se apartó dél, y entonces Andrés respiró un poco y dio a entender que las palabras de Preciosa le habían aprovechado. (P. 67).

Es decir que Andrés no vuelve en sí gracias al ensalmo que Preciosa acepta declarar justo después a petición del padre de Andrés.

Aquí la poesía que es invitación algo juguetona a la confianza y paciencia, es una respuesta a la alabanza de Preciosa en el soneto del paje-poeta:

Cuando Preciosa el panderete toca

y hiere el dulce son los aires vanos, perlas son, que derrama con las manos; flores son, que despide de la boca; suspensa el alma, y la cordura loca queda a los dulces actos sobrehumanos, que de limpios, de honestos, y de sanos, su fama al cielo levantado toca.

Colgadas del menor de sus cabellos Mil almas lleva, y a sus plantas tiene Amor rendidas una y otra flecha.

Ciega y alumbra con sus soles bellos, su imperio amor por ellas le mantiene, Y aun más grandezas de su ser sospecha. (Pp.65-66).

Estos versos alabados tanto por Rubén Darío como por Luis Cernuda recogen varios tópicos de la poesía amorosa como las perlas, los soles, los cabellos, las flechas de Cupido (la de oro que engendra amor y la de plomo que engendra odio) y subrayan la fuerza del amor que ciega, embelesa y enajena como lo sugiere el oxímoron "la cordura loca / queda a los dulces actos sobrehumanos".

El poder de seducción de Preciosa aquí evocado confirma lo que destacaba el primer poema del paje. En esas redondillas, la mirada ocupaba un lugar central como lo revelan los versos siguientes: 
Que un basilisco se cría

en ti que mata mirando. (P. 42).

Haces, oh niña,que estén

tus hechizos en tus ojos.

En sus fuerzas nos adelantas, pues bailando nos admiras, y nos matas si nos miras. y nos encantas, si cantas.

De cien mil modos hechizas, hables, calles, cantes, mires, o te acerques, o te retires, el fuego de amor atizas. (P. 43).

Los términos "hechizar" y "hechizos", la imagen del basilisco, el juego sobre la muerte metafórica causada por el amor subrayan la atracción irresistible que ejerce la gitanilla sobre este personaje que representa un obstáculo y un peligro para las aspiraciones matrimoniales de Preciosa y Andrés.

Su presencia que se manifiesta de manera enigmática en un primer tiempo, a través de estas dos composiciones poéticas, podría ser un símbolo de que la poesía turba lo puro. Y la buenaventura sería de manera especial una ilustración de ello por su carácter disonante. Afín a la poesía burlesca dista de la poesía bucólica en la que se inspira el canto amebeo de Clemente y Andrés, interpretado cuando ya no son rivales sino "camaradas y grandes amigos, asegurándolo todo la buena intención de Clemente y el recato y prudencia de Preciosa, que jamás dio ocasión a que Andrés tuviese della celos” (P. 90).

El entrelazamiento estrófico donde cada interlocutor inicia su respuesta con el último verso del anterior es significativo de esa relación que hace posible ese coro de dos voces. El decorado propio de la narración pastoril viene esbozado así:

Sucedió, pues, que estando el aduar alojado en un valle cuatro leguas de Murcia, una noche, por entretenerse, sentados los dos, Andrés al pie de un 
alcornoque, Clemente al de una encina, cada uno con una guitarra, convidados del silencio de la noche, comenzando Andrés y respondiendo Clemente, cantaron estos versos. (P. 9I).

Sorprende el instrumento músico aludido ya que no es el más característico de los pastores que suelen tocar zampoñas, rabeles, chirumbeles, sino de los personajes de baja extracción social relacionados con el universo picaresco, según Jorge García López. ${ }^{\text {I2 }}$

Estas estrofas aliradas alaban a Preciosa por su hermosura, su honestidad y su fuerza embelesadora como lo ilustran los versos siguientes cantados por Andrés:

Paz en las almas, gloria en los sentidos, se siente cuando canta

la Sirena que encanta

y adormece a los más apercibidos,

es tal mi Preciosa

que es lo menos que tiene ser hermosa,

dulce regalo mío,

corona del donaire, honor del brío. (Pp. 92-93).

Preciosa parece responder a esos versos al cantar a continuación:

En esta empresa amorosa

donde el amor entretengo,

por mayor ventura tengo

ser honesta que hermosa.

Y recalca poco después lo esencial que es para ella la honestidad, valiéndose de una metáfora sugestiva :

En este mi bajo cobre, siendo honestidad su esmalte, no hay buen deseo que falte, ni riqueza que no sobre. (P. 93).

\footnotetext{
${ }^{\mathrm{I} 2}$ Cervantes (200I:9I).
} 
Una vez acabado el canto, el narrador cuida de hacer hincapié nuevamente en esa cualidad alabada más que la hermosura: "Pasaron entre los tres discretas razones, y Preciosa descubrió en las suyas su discreción, su honestidad y su agudeza” (p. 94) .

El lector puede interrogarse sobre las razones de tanta insistencia : ¿la imagen del esmalte no serviría para hacer pensar que es una mera apariencia y que no es oro todo lo que reluce?

La doble condición de Preciosa (gitana de adopción y noble por su linaje) encuentra su mejor expresión en la poesía donde alardea de una audacia que es el reflejo de la osadía del mismo Cervantes al conceder a una gitana el protagonismo de su primera novela ejemplar. A través de ella, se atreve a afirmar el valor individual de las personas como lo destacan los últimos versos que canta:

Si las almas son iguales, podrá el de un labrador, igualarse por valor con las que son imperiales. (P. 94).

Se vale de la voz de un ser marginado para denunciar un mundo jerarquizado injusto y lleno de hipocresía. Lo mismo hizo con el loco caballero andante don Quijote de la Mancha.

La poesía resulta ser el modo de expresión privilegiado para ello y su importancia en la novela puede explicarse no sólo por la influencia de las dos églogas de Juan del Encina “representadas en reqüesta de unos amores” en que se inspiró el escritor alcalaíno según Stanislav Zimic ${ }^{13}$ sino también por su rara valía, que el paje poeta pondera así: "Hase de usar de la poesía, como de una joya preciosísima, cuyo dueño no la trae cada día, ni a cada paso, sino cuando convenga y sea razón que la muestre"; y a continuación propone la definición siguiente de la poesía:

\footnotetext{
${ }^{13}$ Zimic (1996:2).
} 
La poesía es una bellísima doncella, casta, honesta, discreta, aguda, retirada, y que se contiene en los límites de la discreción más alta. Es amiga de la soledad; las fuentes la entretienen, los prados la consuelan, los árboles la desenojan, las flores la alegran, $\mathrm{y}$, finalmente, deleita y enseña a cuantos con ella comunican. (P. 6o).

El empleo de los superlativos "preciosísima” y "bellísima” así como la insistencia en la honestidad y discreción invitan a una identificación simbólica de Preciosa con la poesía.

La visión que se ofrece de ésta lleva a recordar las referencias alegóricas en El viaje del Parnaso y en El Quijote que la convierten en soberana de las otras artes y ciencias. ${ }^{14}$ Como puso de realce José Montero Reguera, en La Gitanilla se hace una defensa de la poesía como "algo que tiene valor en sí mismo, no en función de la fama, prestigio o consideración social que se puedan alcanzar, sino como algo que el ser humano hace por disfrute personal o del prójimo". ${ }^{\text {is }}$

Los poemas presentes en la obra se insertan en diversas tradiciones, bucólica, amorosa, burlesca que Cervantes recrea, del mismo modo que en el Quijote se apoya en distintos géneros narrativos. Juega con los códigos, obligando al lector a estar siempre alerta para descifrar los indicios de ambigüedad, de disonancia o desfase.

La desenvoltura de Preciosa se manifiesta ante todo en la poesía, su honestidad tantas veces proclamada le da una libertad extraordinaria para denunciar la deshonestidad que encarnan el teniente y su mujer doña Clara.

Goza también de una inesperada libertad otro personaje femenino, Altisidora que al contrario de las demás mujeres del Quijote se revela experta en el terreno de la burla verbal. Dos veces se expresa en versos, primero en el capítulo 44, en una seudodeclaración de amor al caballero manchego, invirtiendo así los papeles habituales, lo que llevó a Monique Joly a decir

\footnotetext{
${ }^{14}$ Spieker (1975/76). Véase también Güntert (I972:124).

${ }^{15}$ Montero Reguera (201 3:35).
} 
que era una variación "en torno al tema del mundo al revés" ${ }^{16}$ La comicidad del romance estriba en la oposición entre la desenvoltura de la doncella y la pudibundez de don Quijote:

más honesto y más bendito que el oro fino de Arabia. ${ }^{17}$

Esta desenvoltura se manifiesta aún más en los versos del capítulo 57 precedidos por las palabras siguientes: "alzó la voz la desenvuelta y discreta Altisidora y en son lastimero dijo”. Y una vez terminada la endecha, el narrador precisa:

Quedó la duquesa admirada de la desenvoltura de Altisidora, que aunque la tenía por atrevida, graciosa y desenvuelta, no en grado que se atreviera a semejantes desenvolturas; y como no estaba advertida desta burla, creció más su admiración". (P. I092).

Si la declarada honestidad de Preciosa sirve de contrapeso a su desenvoltura, no ocurre lo mismo con Altisidora cuyo retrato la emparenta con una mujer de mala vida por tener "la nariz algo chata", por no ser "nada de manca” (p. 989), expresión que recuerda las "manos de plata” de la señora tenienta a quien la gitanilla dice la buenaventura, y también por asimilarse a “ una corderilla / que está muy lejos de oveja” (p. I09o). Pero no se afirma claramente su deshonestidad, probablemente porque pertenece al universo ducal y no se pueden cargas las tintas. Sin embargo, se sitúan en el terreno de la sensualidad y del erotismo la falsa acusación del robo de tres tocadores y unas ligas en el segundo poema así como la aspiración expresada en esos versos del capítulo 44:

¡Oh, quién se viera en tus brazos o, si no, junto a tu cama,

\footnotetext{
${ }^{16}$ Joly (1990: 145).

${ }^{17}$ Cervantes (2004:987).
} 
rascándote la cabeza

y matándote la caspa! ${ }^{18}$

Mucho pido y no soy digna

de merced tan señalada:

los pies quisiera traerte,

que a una humilde esto le basta. (P. 988).

La última escena recuerda la figura de la Magdalena.

El carácter delirante de esos versos que se parecen en algún momento a las coplas de disparates se explica, según Monique Joly, por una leve embriaguez imputable a su nombre que recuerda el vino de Auxerre o Altissidorense. ${ }^{19}$

La osadía de la doncella en todo caso puede compararse con la de Preciosa en la buenaventura pero dista el retrato suyo del de Preciosa. Altisidora que se burla del caballero es, de hecho, el blanco de la burla y su poca honestidad es equiparable a la de doña Clara. Cervantes parece haber escogido la poesía para que unas figuras femeninas se expresen lo más libremente posible a través de una serie de recursos metafóricos, de alusiones y de inversiones. El lector descubre así la mirada que echa sobre la condición femenina, sobre la sociedad de su tiempo y valora el juego de la escritura y de la intertextualidad donde crear es recrear.

\section{BibliografíA}

Alzieu, Pierre, Lissorgues, Yvan y Jammes, Robert (i 975), Poesía erótica del Siglo de Oro, Toulouse: France-Ibérie-Recherche.

Casaldu ero, Joaquín (1 969), Sentido y forma de las Novelas ejemplares, Madrid: Gredos.

Cervantes, Miguel de (I999), Obras completas, Madrid: Castalia.

Cervantes, Miguel de (200I), Novelas ejemplares, Barcelona: Crítica, 200 . Edición de Jorge García López con estudio preliminar de Javier Blasco.

Cervantes, Miguel de (2004), Don Quijote de la Mancha, Barcelona: Crítica. Edición del Instituto Cervantes dirigida por Francisco Rico.

Deleito y Piñ uela, José (i 966), También se divierte el pueblo, Madrid: Espasa-Calpe, S. A.

\footnotetext{
${ }^{18}$ Márquez Villanueva (I 995:3 I7) precisa que para la tradición medieval es una expresión de sensualidad.

${ }^{19}$ Joly (1990:90 I-903).
} 
DelPeCh, François (I 990), “Du héros marqué au signe du prophète: esquisse pour l'archéologie d'un motif chevaleresque", Bulletin hispanique, 92, I, pp. $237-257$.

Forcione, Alban (1982), Cervantes and the Humanist Vision. A Study of four Exemplary Novels, Princeton University Press.

González de Amezúa, Agustín (1948), Cervantes creador de la novela corta española, CSIC, Madrid.

Güntert, Georges (1972), “La gitanilla y la poética de Cervantes“, BRAE, LII, pp. Io7- I 34.

Joly, Monique (1993), "En torno a las antologías poéticas de La gitanilla y La ilustre fregona“, Cervantes, Bulletin of the Cervantes Society of America, I 3, 2, pp. 5- 5.

Joly, Monique (1982), La bourle et son interprétation. Recherches sur le passage de la facétie au roman, Toulouse: France-Ibérie-Recherche.

Joly, Monique (1990), "El erotismo en El Quijote: la voz femenina“, Edad de Oro IX, pp. I 37-I 48.

Joly, Monique (1990), "Micro-lecturas: en torno a algunas referencias de Cervantes al vino", Nueva Revista de Filología Hispánica, XXXVIII, 2, pp. 90 I-91 5.

Laffranque, Marie (1974) "Encuentro y coexistencia de dos sociedades en el Siglo de Oro. La gitanilla de Miguel de Cervantes", Actas del V Congreso de la AIH, pp.549-56I.

Lerner, Isaías ( I980), "Marginalidad en las Novelas ejemplares. La gitanilla", Lexis, 4, pp. 47-59.

Márquez Villanueva, Francisco (1985/1986) "La buenaventura de Preciosa“, Nueva Revista de Filología Hispánica, 34, pp. 741-768.

Márquez Villanueva, Francisco (1995), Trabajos y días cervantinos, Alcalá de Henares: Centro de Estudios Cervantinos.

Montero Reguera, José (2013), “La gitanilla: una rei-vindicación de la poesía”, Ínsula, 799-800 pp.34-36.

Spieker, Joseph B. (1975/76), "Preciosa y Poesía (sobre el concepto cervantino de la Poesía y la estructura de La gitanilla)" Explicación de textos literarios, vol. IV-2, pp. 2 1 3-220.

Torres, Bénédicte (2002), Cuerpo y gesto en el Quijote, Alcalá de Henares: Centro de Estudios Cervantinos.

Zimic, Stanislav ( I996), Las Novelas ejemplares de Cervantes, Madrid: Siglo Veintiuno de España Editores S. A.

recibido: septiembre de 2018 aceptado: octubre de 2018 